\title{
THE SEPTEMBER MEETING IN MADISON
}

The forty-fifth summer meeting and twenty-first colloquium of the American Mathematical Society were held at the University of Wisconsin, Madison, Wisconsin, from Tuesday to Friday, September $5-8,1939$, preceded by the summer meeting of the Mathematical Association of America.

The attendance was about three hundred fifty including the following two hundred forty-two members of the Society:

R. P. Agnew, Leonidas Alaoglu, A. A. Albert, G. E. Albert, O. W. Albert, F. E. Allen, R. C. Archibald, H. A. Arnold, J. V. Atanasoff, W. L. Ayres, Reinhold Baer, F. E. Baker, R. H. Bardell, R. C. F. Bartels, J. H. Bell, P. O. Bell, A. A. Bennett, D. L. Bernstein, S. F. Bibb, G. A. Bliss, B. W. Brewer, R. W. Brink, F. L. Brooks, R. E. Bruce, H. E. Buchanan, J. H. Bushey, Jewell H. Bushey, W. H. Bussey, W. D. Cairns, H. H. Campaigne, M. E. Carlen, I. S. Carroll, W. B. Carver, C. R. Cassity, Harold Chatland, E. W. Chittenden, A. H. Clifford, J. B. Coleman, E. G. H. Comfort, L. P. Copeland, J. J. Corliss, Richard Courant, H. S. M. Coxeter, A. R. Crathorne, L. L. Cronvich, E. L. Crow, D. R. Curtiss, H. T. Davis, W. M. Davis, F. F. Decker, L. A. V. DeCleene, C. H. Denbow, Douglas Derry, L. L. Dines, B. F. Dostal, R. H. Downing, Arnold Dresden, R. J. Duffin, J. M. Earl, M. C. Eide, Churchill Eisenhart, Benjamin Epstein, G. C. Evans, G. W. Evans, H. P. Evans, C. J. Everett, L. R. Ford, Tomlinson Fort, J. S. Frame, Bernard Friedman, T. C. Fry, M. G. Gaba, E. R. Garbe, B. E. Gatewood, B. P. Gill, W. O. Gordon, W. C. Graustein, L. M. Graves, V. G. Grove, B. L. Hagen, D. W. Hall, O. G. Harrold, W. L. Hart, W. W. Hart, Camilla Hayden, E. R. Hedrick, E. D. Hellinger, Olaf Helmer, A. D. Hestenes, M. R. Hestènes, Einar Hille, J. J. L. Hinrichsen, D. L. Holl, T. R. Hollcroft, E. M. Hull, M. G. Humphreys, W. A. Hurwitz, D. H. Hyers, M. H. Ingraham, Dunham Jackson, S. B. Jackson, Nathan Jacobson, R. L. Jeffrey, Walter Jennings, C. M. Jensen, Fritz John, M. M. Johnson, E. R. van Kampen, Wilfred Kaplan, A. J. Kempner, R. B. Kershner, P. W. Ketchum, H. R. Kingston, E. E. Knight, Fulton Koehler, R. E. Langer, C. G. Latimer, V. V. Latshaw, D. H. Lehmer, R. A. Leibler, Walter Leighton, C. A. Lester, G. H. Ling, Dorothy McCoy, N. H. McCoy, W. C. McDaniel, J. V. McKelvey, Brockway McMillan, E. J. McShane, C. C. MacDuffee, Saunders MacLane, H. F. MacNeish, Ralph Mansfield, H. W. March, Morris Marden, W. T. Martin, L. C. Mathewson, A. E. May, J. R. Mayor, L. E. Mehlenbacher, D. D. Miller, W. L. G. Mitchell, Virginia Modesitt, W. L. Moore, C. W. Moran, L. J. Mordell, Vladimir Morkovin, D. S. Morse, Marston Morse, David Moskovitz, E. J. Moulton, H. T. Muhly, J. L. Nagel, Tadasi Nakayama, C. J. Nesbitt, Albert Neuhaus, E. N. Oberg, Rufus Oldenburger, L. F. Ollmann, Isaac Opatowski, Alexander Oppenheim, F. W. Owens, H. B. Owens, J. C. Oxtoby, G. A. Parkinson, E. W. Paxson, G. H. Peebles, W. H. Pell, I. E. Perlin, Sam Perlis, G. W. Petrie, H. P. Pettit, Everett Pitcher, G. B. Price, J. W. Querry, Tibor Rad6, W. T. Reid, R. W. Rempfer, R. G. D. Richardson, R. F. Rinehart, G. de B. Robinson, S. G. Roth, W. E. Roth, L. L. Runge, M. G. Scherberg, O. F. G. Schilling, E. R. Schneckenburger, G. E. Schweigert, W. T. Scott, C. E. Sealander, Hyman Serbin, C. G. Shover, R. G. Simond, M. E. Sinclair, E. R. Sleight, M. F. Smiley, C. E. Smith, E. R. Smith, G. W. Smith, 
Virgil Snyder, E. S. Sokolnikoff, I. S. Sokolnikoff, N. E. Steenrod, B. M. Stewart, M. H. Stone, E. B. Stouffer, M. M. Sullivan, Otto Szász, Gabor Szegö, M. E. Taylor, W. C. Taylor, B. J. Tepletsky, R. M. Thrall, Leonard Tornheim, H. C. Trimble, P. L. Trump, A. W. Tucker, H. L. Turrittin, Henry Van Engen, E. B. Van Vleck, J. H. Van Vleck, V. J. Varino, J. I. Vass, Oswald Veblen, G. E. Wahlin, R. J. Walker, A. D. Wallace, J. A. Ward, J. H. Weaver, M. S. Webster, M. J. Weiss, E. T. Welmers G. W. Whaples, P. M. Whitman, G. T. Whyburn, W. M. Whyburn, Norbert Wiener, L. R. Wilcox, L. A. Wolf, M. C. Wolf, F. E. Wood, H. A. Wood.

Many of the members remembered with pleasure the two previous summer meetings of the Society in Madison in 1913 and 1927, and as on the two earlier occasions the University of Wisconsin proved a perfect host. The growth of the Society is reflected in the records of these three meetings. In 1913 there were 57 members present and 46 papers were presented; in 1927, 133 members and 69 papers; while at this meeting there were 242 members and 120 papers, the largest number of papers ever presented at any one meeting of the Society.

The program was featured by two sets of Colloquium Lectures. The lectures on Structure of algebras were delivered by Professor A. A. Albert of the University of Chicago on Tuesday afternoon, Wednesday, Thursday, and Friday mornings. The lectures on Convex bodies were delivered by Professor M. H. Stone of Harvard University on Wednesday morning, Thursday afternoon, and Friday morning. Professor Albert's lectures appeared as volume 24 of the Colloquium Publications at the time of the meeting and Professor Stone's lectures will appear as a volume in this series at some future date. This was the third Madison Colloquium, the previous ones being given by Professors L. E. Dickson and W. F. Osgood in 1913, and by Professors E. T. Bell and Anna Pell Wheeler in 1927.

President G. C. Evans presided at each initial Colloquium Lecture and at the general session Wednesday morning. Vice-President R. E. Langer presided at the general session Thursday afternoon. The presiding officers at the sectional sessions were as follows: Analysis, Professors E. J. McShane, H. E. Buchanan, and R. P. Agnew; Algebra, Professors D. H. Lehmer, and C. C. MacDuffee; Algebra and Geometry, Professors Virgil Snyder and H. S. M. Coxeter; Topology, Professor Tibor Radó.

The dormitories of the University were opened to the members of both organizations and their guests, and headquarters for the meetings were at the Gatehouse.

Arrangements for the entertainment of those attending the meetings were excellent. Swimming and boating were available on Lake Mendota at all times, and arrangements were made for golf and tennis. On Monday and Tuesday afternoons the ladies of the local De- 
partment of Mathematics served tea in the Pine Room of the refectory. On Wednesday afternoon there were excursions to the Banta Publishing Company, the United States Forest Products Laboratory, and the Yerkes Observatory. In addition on Wednesday there was a trip around Lake Mendota by launch and a picnic on the lake shore at Picnic Point.

A joint dinner for members of the Society and Association and their guests was held at the Loraine Hotel on Thursday evening, President G. C. Evans presiding as toastmaster. Dean G. C. Sellery of the University of Wisconsin welcomed the mathematicians on behalf of the University. Professor W. C. Graustein spoke of the unfortunate postponement of the International Congress. Professor Oswald Veblen and Dr. T. C. Fry told of the plans for the new Mathematical Reviews and participated in the ensuing lively discussion. Professor W. D. Cairns spoke of amusing and interesting experiences as Secretary of the Association. At the close of the dinner Dean E. B. Stouffer presented a joint resolution on behalf of both mathematical organizations thanking the President and officers and the members of the Department of Mathematics of the University of Wisconsin, and the officials of the Banta Publishing Company for their competent arrangements and cordial hospitality. The attendance at the dinner was two hundred fifty-one.

The Council met on Wednesday, September 6, at 8:15 P.M. in the small dining room of the refectory. An adjourned meeting was held in the Loraine Hotel after the dinner on the evening of September 7.

The Secretary announced the election of the following thirty persons to membership in the Society:

Professor Olin Blair Ader, Wofford College;

Dr. Burns W. Brewer, Texas Agricultural and Mechanical College;

Professor Charles Edwin Bures, The College of Idaho, Caldwell, Idaho;

Dr. Nathaniel Coburn, University of Texas;

Mr. Robert Coleman, Jr., Wilberforce University, Wilberforce, Ohio;

Mr. Thomas Carlson Doyle, Princeton University;

Mr. William Frederick Eberlein, Shawano, Wis.;

Miss Laura Christine Efird, Hugh Morson High School, Raleigh, N. C.;

Mr. Raymundo Acosta Favila, Manila, P. I.;

Dr. Floyd Grayston Fisher, University of Santa Clara;

Professor John Steiner Gold, Bucknell University;

Dr. Ernst D. Hellinger, Northwestern University;

Mr. John S. Hickman, Rochester Junior College, Rochester, Minn.;

Dr. Gabriel Horvay, New York, N. Y.;

Dr. Hsien-Yü-Hsü, Washington University, St. Louis, Mo.;

Mr. Fulton Koehler, University of Minnesota;

Mr. Ogden Lillard, New York, N. Y.; 
Mr. John Lovell Loughborough, Lincoln Institute, Hollywood, Calif.;

Sister Mary Michael Maloney, D'Youville College, Buffalo, N. Y.;

Mr. F. C. W. Olson, American Can Company, Maywood, Ill.;

Professor Edward Monroe Joseph Pease, Rhode Island State College;

Professor Joseph Alphonso Pierce, Atlanta University, Atlanta, Ga.;

Dr. Jenny Eugenie Rosenthal, Brooklyn College;

Dr. Michael A. Sadowsky, Armour Institute of Technology;

Mr. Charles Louis Seebeck, Jr., University of North Carolina;

Mr. Robert Richmond Singleton, Princeton, N. J.;

Dr. Wolfgang Sternberg, New York, N. Y.;

Mr. Duane Morton Studley, Colorado Springs, Colo.;

Mr. Benjamin Joseph Trapani, Pennsylvania State College;

Dr. John William Theodore Youngs, Ohio State University.

The following two persons were admitted to the Society in accordance with the reciprocity agreement with the London Mathematical Society:

Professor W. H. McCrea, Queen's University, Belfast, Ireland;

Professor Frederick Riesz, University of Szeged, Szeged, Hungary.

The following appointments by President Evans were reported: as representative of the Society at the Sesquicentennial Celebration of Georgetown College (now Georgetown University) on May 28-June 3 , Professor A. E. Landry; as representative of the Society at the celebration of the fiftieth anniversary of the founding of the University of New Mexico on June 4-5, Professor C. V. Newsom; as representative of the Society at the celebration of the fiftieth anniversary of the founding of the Catholic University of America on November 11-13, Professor F. D. Murnaghan; to replace Professor C. R. Adams on the Committee to consider freer methods of nominating and electing members-at-large in the Council, Professor L. R. Ford; as a representative of the Society on the Council of the American Association for the Advancement of Science for 1939, Professor L. L. Dines.

Meetings of the Society were set as follows: at the California Institute of Technology on December 2, 1939, and in Chicago on April 12-13, 1940.

Professor Oswald Veblen (chairman) and Drs. T. C. Fry and Warren Weaver were continued in charge of the new journal, Mathematical Reviews. An article concerning this new development of the Society's work appeared in the September number of this Bulletin.

In view of the distressful world situation, the International Congress of Mathematicians which was to be held at Cambridge, Massachusetts, in September, 1940, was postponed. An Emergency Executive Committee, consisting of Professors G. D. Birkhoff, W. C. Graustein, Einar Hille, M. H. Ingraham, J. R. Kline, Marston Morse, 
R. G. D. Richardson, and M. H. Stone, was appointed to act during the interim.

A revision of the by-laws of the Society to facilitate the handling of the financial business which has grown to such considerable proportions was approved and this revision will be submitted to the Society at the October meeting.

A committee on the reorganization of the business of the Secretariat was appointed, consisting of Professors L. M. Graves (chairman), W. B. Fite, J. R. Kline, C. C. MacDuffee, E. J. McShane, W. T. Martin, and C. B. Morrey.

Professor Tomlinson Fort for the Editorial Committee on the Bulletin announced that the edition beginning with the September 1939 issue will be increased by one hundred copies.

Professor C. N. Moore was reappointed as representative of the Society on the board of the American Year Book for a period of three years.

Professors Oystein Ore and G. T. Whyburn were appointed Colloquium Lecturers for 1941 with the understanding that one or both may be moved forward to 1940. It was announced that Volumes 23 and 24 of the Colloquium series by Professors Gabor Szegö and A. A. Albert were off the press.

The titles and cross-references to abstracts of papers read at this meeting are given below. Papers numbered 1 to 11 were presented Tuesday afternoon; papers 12 to 14, Wednesday morning; papers 15 to 40, Thursday morning; papers 41 to 44, Thursday afternoon; and papers 45 to 54, Friday morning. Papers 55 to 120 , whose abstract numbers are followed by the letter $t$, were read by title. Paper number 1 was read by Professor Moskovitz, 30 by Dr. Kershner, 40 by Dr. Hall, 45 by Dr. Scott, 46 by Professor Martin, and 48 by Dr. Duffin. Dr. Andrew Sobczyk was introduced by Professor H. F. Bohnenblust, Mr. Bernard Dimsdale by Professor Dunham Jackson, Professors A. E. Ross and W. S. Kimball by Professor W. L. Ayres, and Dr. I. Malkin by Professor W. T. Martin.

1. David Moskovitz and L. L. Dines: On the supporting-plane property of a convex body. (Abstract 45-9-351.)

2. M. F. Smiley: $A$ note on measure functions in a lattice. (Abstract 45-7-278.)

3. D. H. Hyers: A generalization of Fréchet's differential. (Abstract 45-9-325.)

4. Andrew Sobczyk: Projections in Minkowski and Banach spaces. (Abstract 45-9-378.) 
5. Wilfred Kaplan: Regular curve-families filling the plane. (Abstract 45-9-328.)

6. Isaac Opatowski: Differential equations containing functionals of unknown functions. (Abstract 45-9-357.)

7. H. A. Arnold: Defective groups. (Abstract 45-9-296.)

8. R. M. Thrall: A note on groups of class 3. (Abstract 45-9-381.)

9. Reinhold Baer: Nilpotent groups and their generalizations. (Abstract 45-9-299.)

10. P. M. Whitman: Free lattices. (Abstract 45-9-390.)

11. G. W. Whaples: On the structure of moduls with a commutative algebra as operator domain. Preliminary report. (Abstract 45-9-389.)

12. L. R. Wilcox: A new foundation for projective differential geometry. (Abstract 45-9-393.)

13. E. J. McShane: Generalized curves. (Abstract 45-9-342.)

14. Everett Pitcher: Critical points of a map to a circle. (Abstract 45-9-362.)

15. B. E. Gatewood: Thermal stresses in long cylindrical bodies. (Abstract 45-9-314.)

16. R. E. Langer: On the stability of the laminar flow of a viscous fluid. (Abstract 45-9-332.)

17. Dunham Jackson: Orthogonal polynomials with auxiliary conditions. (Abstract 45-9-326.)

18. Bernard Dimsdale: Degree of approximation by linear combinations of powers. (Abstract 45-9-309.)

19. G. H. Peebles: On equivalence of certain types of series of orthonormal functions. (Abstract 45-9-358.)

20. E. N. Oberg: $A$ note on a certain phase of best approximation. (Abstract 45-9-354.)

21. M. S. Webster: Note on certain Lagrange interpolation polynomials. (Abstract 45-9-388.)

22. Bernard Friedman: Fourier coeffcients of bounded functions. (Abstract 45-9-313.)

23. L. E. Mehlenbacher: Determination of the asymptotic behavior of the solutions of differential equations of the Fuchsian type; the case of $n+2$ regular singular points. (Abstract 45-7-282.)

24. H. S. M. Coxeter: A new form of coordinates for the polytope $2_{21}$ whose twenty-seven vertices correspond to the lines on the general cubic surface. (Abstract 45-9-308.)

25. T. R. Hollcroft: Anomalous systems of primals. (Abstract 459-324.)

26. P. O. Bell: Projective invariants of a curve on a surface. (Abstract 45-9-301.) 
27. H. T. Muhly: Valuations and infinitely near algebraic loci. II. Preliminary report. (Abstract 45-9-352.)

28. C. G. Latimer: A class of diophantine equations. (Abstract 459-333.)

29. D. H. Lehmer: Certain congruential properties of spherical harmonics. (Abstract 45-9-334.)

30. Philip Hartman and R. B. Kershner: On some limit theorems for number theoretic functions. (Abstract 45-9-322.)

31. A. E. Ross: $A$ note on representation of integers by positive quaternary quadratic forms. (Abstract 45-9-369.)

32. H. H. Campaigne: Suschkewitsch correspondences. (Abstract 45-9-307.)

33. L. F. Ollmann: On cubic ring graphs. (Abstract 45-9-356.)

34. W. L. Ayres: Peano spaces as the theory of continuous images of intervals. (Abstract 45-9-297.)

35. A. D. Wallace: On quasi-monotone transformations. (Abstract 45-9-387.)

36. G. T. Whyburn: Non-alternating interior retracting transformations. (Abstract 45-7-281.)

37. N. E. Steenrod: Homology groups of the complement of a closed set in an n-sphere. (Abstract 45-9-379.)

38. Edith R. Schneckenburger: On 1-bounding monotonic transformations which are equivalent to homeomorphisms. (Abstract 45-9372.)

39. O. G. Harrold: Topological properties of rectifiable continua. (Abstract 45-9-321.)

40. D. W. Hall (National Research Fellow) and G. T. Whyburn: An analysis of arc-preserving transformations. (Abstract 45-11-399.)

41. Fritz John: Special solutions of certain difference equations. (Abstract 45-9-327.)

42. W. T. Reid: Sufficient conditions by expansion methods for multiple integral problems of the calculus of variations. (Abstract 45-9-366.)

43. Olaf Helmer: The principal ideal theorem in domains of integral functions. (Abstract 45-9-323.)

44. R. P. Agnew: On kernels of faltung transformations. (Abstract 45-9-293.)

45. W. T. Scott and H. S. Wall: A convergence theorem for continued fractions. (Abstract 45-7-277.)

46. Stefan Bergmann and W. T. Martin: On the existence of a function of integrable square which satisfies an infinite system of integral relations. (Abstract 45-9-302.) 
47. Benjamin Epstein: Growth properties of analytic functions of two complex variables. (Abstract 45-9-311.)

48. A. C. Schaeffer and R. J. Duffin: A refinement of the inequality of the brothers Markoff. (Abstract 45-9-371.)

49. I. E. Perlin: Indefinitely differentiable functions with prescribed least upper bounds. (Abstract 45-9-359.)

50. Margarete C. Wolf: Transformations of bases for relative sets over a non-commutative field. (Abstract 45-9-394.)

51. Albert Neuhaus: On products of normal semi-fields. (Abstract 45-9-353.)

52. N. H. McCoy: A generalization of Ostrowski's theorem on matric identities. (Abstract 45-9-339.)

53. Rufus Oldenburger: Infinite powers of matrices and characteristic roots. (Abstract 45-9-355.)

54. W. E. Roth: On the unilateral equation in matrices. II. (Abstract $45-9-370$.)

55. Ingo Maddaus: On types of "weak" convergence in normed vector spaces. Preliminary report. (Abstract 45-9-337-t.)

56. Richard Brauer: On groups whose order is divisible by the first power of a prime. II. Preliminary report. (Abstract 45-9-304-t.)

57. Deane Montgomery and Leo Zippin: Topological transformation groups. (Abstract 45-9-348-t.)

58. P. R. Halmos: On a necessary condition for the strong law of large numbers. (Abstract 45-9-320-t.)

59. H. A. Simmons and J. F. Paydon: On the shortest time of fall from a curve to a point. (Abstract 45-9-377-t.)

60. D. W. Hall (National Research Fellow) and J. L. Kelley: On continuous collections of orbits. (Abstract 45-9-319-t.)

61. W. J. Trjitzinsky: General theory of singular integral equations with real kernels. (Abstract 45-9-382-t.)

62. W. S. Kimball: Partial derivatives of derivatives. (Abstract. 45-9-330-t.)

63. Garrett Birkhoff and John Dyer-Bennet: $A$ note on real algebraic functions. (Abstract 45-5-162-t.)

64. Garrett Birkhoff: Lattice theory of Browerian logic. (Abstract 45-7-260-t.)

65. Morgan Ward: An arithmetical characterization of a modular lattice. (Abstract 45-7-280-t.)

66. J. F. Ritt: On intersections of algebraic differential manifolds. (Abstract 45-7-274-t.)

67. J. F. Ritt and E. R. Kolchin: On certain ideals of differential polynomials. (Abstract 45-7-275-t.) 
68. E. R. Lorch: Means of iterated transformations in reflexive vector spaces. (Abstract 45-7-270-t.)

69. R. P. Boas (National Research Fellow): Integral functions bounded on the real axis. (Abstract 45-7-261-t.)

70. R. H. Cameron: Extensions of Wiener's general Tauberian theorem. (Abstract 45-7-262-t.)

71. Oystein Ore and J. E. Eaton: Remarks on multigroups. (Abstract 45-7-273-t.)

72. J. J. De Cicco: The differential geometry of the curves of the Kasner plane. (Abstract 45-7-264-t.)

73. J. J. De Cicco: The conics of the Kasner plane. (Abstract 45-7265-t.)

74. R. P. Dilworth: A characterization of complemented modular lattices. (Abstract 45-7-266-t.)

75. R. P. Dilworth: Note on the prime elements of a modular lattice. (Abstract 45-7-267-t.)

76. Morgan Ward: The ideal operators of a lattice. (Abstract 45-7289-t.)

77. Barkley Rosser: $A$ new lower bound for the exponent in the first case of Fermat's last theorem. (Abstract 45-7-283-t.)

78. W. T. Scott and H. S. Wall: A convergence theorem for continued fractions. II. (Abstract 45-7-285-t.)

79. Walter Leighton: Proper continued fractions. (Abstract 45-9290-t.)

80. G. T. Whyburn: On the interiority of real functions. (Abstract 45-9-392-t.)

81. G. T. Whyburn: A relation between interior and non-alternating transformations. (Abstract 45-9-391-t.)

82. M. S. Knebelman: Scalar invariants of the vector vortex excess. (Abstract 45-9-331-t.)

83. W. T. Puckett: On regular transformations. (Abstract 45-9364-t.)

84. J. F. Ritt and H. W. Raudenbush: Ideal theory and algebraic difference equations. (Abstract 45-9-367-t.)

85. Garrett Birkhoff: Neutral elements in general lattices. (Abstract 45-9-303-t.)

86. D. C. Lewis: The separability of Pfaffian transformations. (Abstract 45-9-336-t.)

87. C. W. Vickery: On two different types of linear continua. (Abstract 45-9-385-t.)

88. C. W. Vickery: On spaces $\left(V_{\omega_{\alpha}}\right)$ and spaces $\Lambda_{\omega_{\alpha}}$. (Abstract 459-384-t.) 
89. C. W. Vickery: Types of limit points in spaces (V). (Abstract 45-9-386-t.)

90. C. W. Vickery: A theorem on abstract sets. (Abstract 45-9383-t.)

91. Edward Kasner and J. J. De Cicco: Trihornometry of second order. (Abstract 45-9-329-t.)

92. Jakob Levitzki: On multiplicative systems. (Abstract 45-9335-t.)

93. L. M. Graves: Some general approximation theorems. (Abstract 45-9-317-t.)

94. L. M. Graves: On the fundamental lemma of Haar in the calculus of variations. (Abstract 45-9-316-t.)

95. J. W. T. Youngs: Arc-spaces. (Abstract 45-9-395-t.)

96. J. W. T. Youngs: Generalized cyclic elements. (Abstract 45-9396-t.)

97. Reinhold Baer: $A$ Galois theory of linear systems over commutative fields. (Abstract 45-9-298-t.)

98. Deane Montgomery and Leo Zippin: Transformation groups characterizing certain three-manifolds. (Abstract 45-9-349-t.)

99. C. B. Morrey: The problem of Plateau on a Riemannian manifold. Preliminary report. (Abstract 45-9-350-t.)

100. D. W. Hall (National Research Fellow): On pointwise periodic homeomorphisms in the plane. (Abstract 45-9-318-t.)

101. E. J. McShane: Necessary conditions for a minimum in generalized-curve problems of the calculus of variations. (Abstract 45-9343-t.)

102. E. J. McShane: Existence theorems for Bolza problems in the calculus of variations. (Abstract 45-9-344-t.)

103. E. J. McShane: An estimate for the Weierstrass $\mathcal{E}_{\text {-function. }}$ (Abstract 45-9-340-t.)

104. E. J. McShane: A remark concerning sufficiency theorems for the problem of Bolza. (Abstract 45-9-341-t.)

105. I. Malkin: On the elastic problem of the plate. Preliminary report. (Abstract 45-9-338-t.)

106. M. S. Robertson: Typically-real functions with $a_{n}=0$ for $n \equiv 0$ $\bmod 4$. (Abstract 45-9-368-t.)

107. W. T. Reid: $A$ theorem on continuous functions in abstract spaces. (Abstract 45-9-365-t.)

108. I. J. Schoenberg: On local convexity in euclidean spaces. (Abstract 45-9-373-t.)

109. Everett Pitcher: Identification of two subsets. (Abstract 459-363-t.) 
110. B. J. Pettis: Absolutely continuous functions in vector spaces. (Abstract 45-9-360-t.)

111. B. J. Pettis: The uniform differentiation of families of numerical functions. (Abstract 45-9-361-t.)

112. R. P. Agnew: On translations of functions and sets. (Abstract 45-9-294-t.)

113. F. A. Ficken: Cones and vector spaces. (Abstract 45-9-312-t.)

114. R. S. Burington: On transient similarity and equivalence in linear networks. (Abstract 45-9-305-t.)

115. A. D. Michal: Fréchet differentials and M-differentials in Banach spaces. (Abstract 45-9-346-t.)

116. A. D. Michal: $A$ differential in linear topological spaces. (Abstract 45-9-345-t.)

117. A. D. Michal, R. Davis, and Max Wyman: Polygenic functions in general analysis. (Abstract 45-9-347-t.)

118. Warren Ambrose: Some properties of measurable stochastic processes. (Abstract 45-9-295-t.)

119. Gabor Szegö: On the gradient of solid harmonic polynomials. (Abstract 45-11-403-t.)

120. Ben Dushnik and E. W. Miller: Concerning similarity transformations of linearly ordered sets. (Abstract 45-11-397-t.)

W. L. Ayres, Associate Secretary 